Article

\title{
Date Seeds (Phoenix dactylifera L.) Valorization for Boilers in the Mediterranean Climate
}

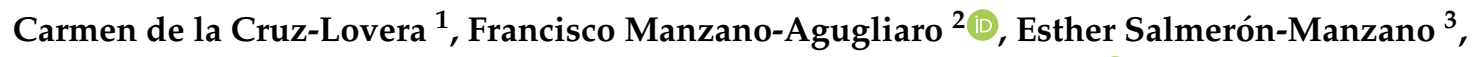 \\ José-Luis de la Cruz-Fernández ${ }^{1}$ and Alberto-Jesus Perea-Moreno ${ }^{1, * \mathbb{C}}$ \\ 1 Departamento de Física Aplicada, Universidad de Córdoba, ceiA3, Campus de Rabanales, 14071 Córdoba, \\ Spain; z52crloc@uco.es (C.d.1.C.-L.); fa1crfej@uco.es (J.-L.d.l.C.-F.) \\ 2 Department of Engineering, ceiA3, University of Almeria, 04120 Almeria, Spain; fmanzano@ual.es \\ 3 Faculty of Law, Universidad Internacional de La Rioja (UNIR), Av. de la Paz, 137, 26006 Logroño, Spain; \\ esther.salmeron@unir.net \\ * Correspondence: aperea@uco.es; Tel.: +34-957-212-633
}

Received: 29 December 2018; Accepted: 29 January 2019; Published: 29 January 2019

check for updates

\begin{abstract}
Energy saving is a global priority, as it is helping both energy and environmental sustainability by reducing $\mathrm{CO}_{2}$ emissions. The search for new energy solutions is therefore necessary. In the Mediterranean climate, resources are generally scarce, and all energy sources need to be explored, including biomass from agricultural or industrial waste. There is a clear upward trend in date worldwide production, having doubled its world production in the last 10 years, and this trend is particularly relevant for Mediterranean climate countries, especially in North Africa and nearby countries. This study analyzes the properties associated with the date seed (Phoenix dactylifera L.) to evaluate its suitability and viability as a new biofuel. Specifically, the viability of replacing the existing gas boiler in a university building in the south of Spain with a system of biomass boilers using this biomass was analyzed as a case study. The results reveal that this biomass has HHV values very similar to those of other biomass sources, $19.121 \mathrm{MJ} / \mathrm{kg}$. With the replacement of the gas boiler by a biomass that uses the date seed, a reduction of 95 tons of $\mathrm{CO}_{2}$ per year is obtained and an economic saving of more than $66 \%$ is achieved. In short, this work opens new perspectives for the use of this biomass of date seed in boilers and it is an efficient solution for large public buildings such as the buildings of Mediterranean climate universities.
\end{abstract}

Keywords: date seed; sustainability; biomass boiler; renewable energy; $\mathrm{CO}_{2}$ reduction; energy efficiency

\section{Introduction}

Sustainable development promotion should prioritize sustainable technologies [1] such as clean and sustainable energies, providing importance to energy efficiency [2] and to the reduction of environmental pollution [3]. In this way, sustainable development promotion also creates solutions that encourage the reduction of emissions [4]. However, it should not be forgotten that policy is particularly important, such as for limiting the use of non-renewable fuels or plans to stop global warming. More and more policies are seeking energy efficiency and the rational use of energy, which reduce costs for companies and individuals [5]. The clearest example is the Paris agreement of 2015, which promotes a global action plan to limit global warming to below $2{ }^{\circ} \mathrm{C}$ [6].

The building industry has a greater impact on sustainable development than others due to its high energy consumption [7], and is therefore one of these sectors that requires more attention [8]. Measures are framed within all the steps in which this industry is involved in order to reduce energy consumption by incorporating energy efficiency strategies in the design [9], construction and management of 
buildings [10,11], as well as in the application of technology to improve the efficiency of existing buildings [12], including the retrofit strategies [13].

An efficient building will be one that consumes little energy and that a large part of that energy would be of renewable origin [14]. This energy efficiency is measured by $\mathrm{CO}_{2}$ emissions or by the consumption of non-renewable primary energy derived from final energy consumption (electricity or fuels). At the end of 2018, the policy became more and more strict, and near zero energy consumption became part of a compulsory legal specification for constructors of buildings. The standard EN15251 specifies indoor environmental criteria that have an impact on energy efficiency. Air quality, lighting and acoustics are some of the environmental parameters it regulates [15]. This framework presents us with the study of energy efficiency in public buildings as not only a subject with an increasing interest, but also makes it mandatory to study new measures and seek solutions to promote greater energy efficiency in local institutions [16].

There has been a growing interest in recent times towards energy efficiency and sustainability in universities, acquiring this important knowledge in creating an increasingly cleaner and more sustainable future. The energy consumption of buildings is largely dependent on the criteria used for the design and operation of the interior space. Aspects such as lighting, noise, ventilation or temperature are of vital importance. Because of this, they can even have an impact on a state of health of a person or their work efficiency [16]. Today, in industrialized countries, city dwellers spend $60 \%-80 \%$ of their time in enclosed spaces, so poor quality living conditions can seriously affect people. If these enclosed spaces are educational buildings, the quality of the indoor environment has direct repercussions on the performance and concentration of students and other staff working in them. In order to improve the living conditions of users inside buildings, it is necessary to implement self-monitoring plans for indoor environmental quality [17].

Once a conceptual framework has been established, there is a need to establish what real changes can be made in universities in order to improve their energy efficiency and consequently their environmental impacts. Biomass is becoming more popular as a high sustainable energy source. Its carbon neutral condition and high availability worldwide are making it an appealing choice for new ways of energy in the field. It can be obtained from agricultural and industrial waste and has grown from $9 \%$ to $14 \%$ of total primary energy consumption in the agro-industrial sector. However, it can be discarded by the industry without even being used as an energy source [18]. The most common and widely accepted fuels derived from biomass are pellets, wood chips, firewood or olive seeds $[19,20]$. In recent years, however, more and more waste fruits have been emerging in the marketplace that may be extremely appropriate as biomass sources. Recent studies show the high suitability of other fruit stones such as avocado or mango as biofuel in both domestic or industrial heating facilities [21-23]. This work focuses its attention on the use of biomass as a renewable energy fuel and studies the suitability of date seeds as a solid biofuel to produce heating energy. To achieve this objective, their energetic qualities are described and parameters such as higher heating value, lower heating value, moisture, elemental composition or ash content are evaluated [24].

The date is the fruit obtained from the species Phoenix dactylifera L., popularly called the finger palm, see Figure 1. The production of dates is one of the most important agricultural activities in the arid regions of East Asia and North Asia [25]. They can also be found in southern Europe, the African continent, Asia, Australia, South America and the USA, especially in southern California, Arizona, and Texas [26]. Much agricultural waste is generated from date palms in the most desert-filled areas of the earth and in Mediterranean climates [27]. It is not only produced in the food sector, for humans and animals, but also in the construction sector, including textiles, among others. The tree begins to bear fruit between 3 and 5 years and ripens definitively at the age of 12. In general, there is a clear upward trend in the production of dates. A clear example of this is the increase over time of the metric tons of dates produced. From 4,569,532 metric tons in 1994 has almost doubled production in 2016, reaching $8,460,443$ metric tons produced in 1,353,159 hectares [28]. 


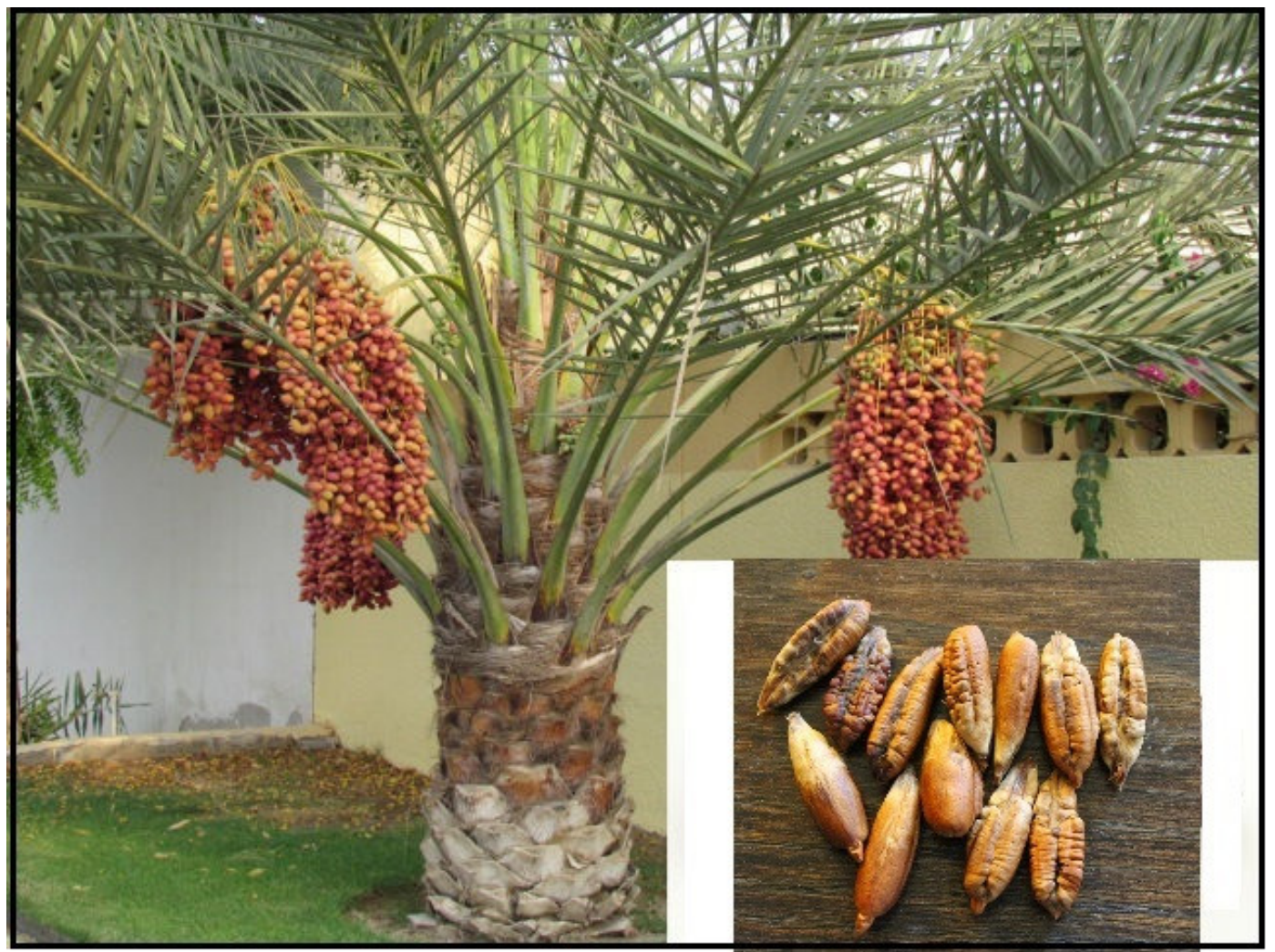

Figure 1. Phoenix dactylifera, popularly called finger palm.

Until the 1990s, Iran and Iraq were the world's largest producers, but currently, the country at the top of the ranking is Egypt with an approximate annual production of 1,470,000 metric tons of dates, assuming $17 \%$ of global date production. Egypt has increased its production more than $100 \%$ since 1993 and currently has a figure of 15,582,000 date palms. Iran and Saudi Arabia follow in this order with more than 1,000,000 metric tons of dates being produced annually in some countries, such as Oman, Egypt, Pakistan and the United Arab Emirates, where there has been a significant increase in the production of dates. In contrast, due to the trade embargo, production decreased in Iraq and in Morocco, due to phytosanitary problems.

For this reason, this article seeks to study new possibilities of date seeds as biofuel for boilers in the Mediterranean climate, using a University in the south of Spain as a case study, in which the calculated carbon footprint has halved from 2012 to 2017, which should improve energy saving in the buildings of the university.

\section{Materials and Methods}

\subsection{Materials}

In order to test the energy efficiency in the Mediterranean climate and economic viability of the date bone as a solid fuel, a building has been chosen located on a university in the south of Spain ( $37^{\circ} 54^{\prime} 55.4^{\prime \prime} \mathrm{N}, 4^{\circ} 43^{\prime} 09.06^{\prime \prime} \mathrm{O}$ ).

The university population has a total of 19,435 people (end 2017), of which 16,610 are students (14,321 Grade, 1636 Masters and 653 Exchange Programs), 2825 staff (1452 teachers, 770 members of administration and services staff and 603 contracted from projects). In this university there is already an indicator of the environmental impact produced by the institution, since environmental awareness is the order of the day. This indicator can help us to know the current situation as far as energy consumption is concerned. This energy indicator is known as the "Carbon Footprint Calculation". The quantification of emissions allows us to be aware of the impact generated by the activity of 
the university on global warming, thus turning the carbon footprint into a valuable awareness tool. Measuring the carbon footprint is a way of evaluating the institution's contribution to climate change. In addition, understanding the emissions generated by its activity, quantifying them and knowing their sources, is necessary as a first step to propose reduction strategies.

The building under study has a cruciform floor, with 5 levels distributed in a semi-basement, ground floor, first floor, second floor and third floor. It has a total living area of 4752 square meters and was built between 1953-1956. Its use is mostly for teaching classes, with departmental spaces and several classrooms.

It is proposed to replace the existing natural gas boiler in the building with the introduction of a biomass boiler system. This use of biomass as an alternative for fossil fuels would provide cost savings and reduction in greenhouse gaseous emissions [29]. The biomass boiler would be used to generate heating in that building, using radiators as terminal elements to thermally acclimatize the spaces. The operation of a biomass boiler is similar to a conventional boiler. First the natural fuel is burned, recovering the heat generated during the combustion of the biomass to heat the water of the circuit of the boiler exchanger, taking the hot water to the heating circuit.

The heating system (hot water heating) uses water as a carrier heat between the boiler and the terminal elements located in the buildings. The boiler (natural gas), located in the semi-basement of the building, heats the cold water, which by means of a transport system and groups of electric pumps that drive the hot water through a network of pipes, reaches the radiators located on each floor of the building, acting as heat exchangers with the environment, heating the temperature of the environment through the temperature of the water that runs through the tubes of these terminal elements. The radiators are monotube, that is to say, they are characterized by having the hot water inlet and the cold water outlet in the same faucet. The hot water runs through the rings of the radiators until the reverse circuit is made, returning the cold water, through the same faucet, to the boiler, where the heating cycle is repeated. The circuits are separated by means of devices called collectors, one for the hot water circuit and the other for the cold water circuit. The number of cast iron radiators distributed throughout all its plants is 346 radiators. It also has gas heaters as domestic hot water devices, with 4 heaters of 100 litters each for use as fountains or sinks. Figure 2 shows the operating diagram of the gas natural boiler.

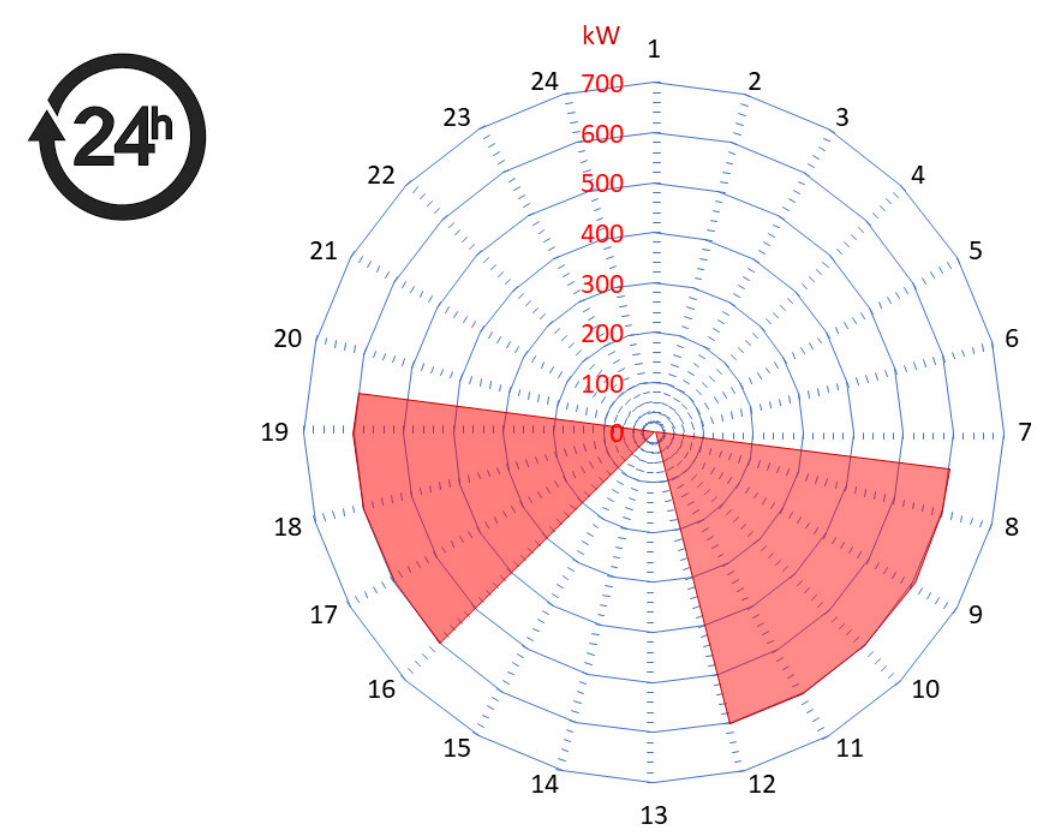

Figure 2. Operating diagram of the natural gas boiler. 


\subsection{Performance Values}

The performance values are specified in Part 1 of standard EN 14961. This is a very generic norm that describes how to classify biomass to be used for energy purposes and details the main commercialized forms of solid biofuels [30]. The indication of the most significant characteristics of biofuels is obligatory and must be quoted in the fuel specification. The characteristics are very varied, depending on different factors. However, the most important parameters are the following where the determination standards (EN) used are referred to: Moisture (EN 14774-1), Ash (EN 14775), Higher heating value (EN 14918), Lower heating value (EN 14918), Total carbon (EN 15104), Total hydrogen (EN 15104), Total nitrogen (EN 15104), Total Sulfur (EN 15289), and Total chlorine (EN 15289).

These characteristics could depend to a large extent on climatic and soil conditions. Water consumption is an important limitation in arid regions where there is an abundance of date palms and makes the crop's drought resistance an important factor.

\subsubsection{Physical Values: Humidity}

One of the most important parameters is the moisture content of the sample. This parameter decisively affects the energy we can obtain from biomass. It is essential that all the water contained in the product is completely removed before the heat is released. There are two data related to moisture content: intrinsic moisture, where meteorological conditions do not influence and the extrinsic moisture, which takes into account several factors such as the climate present during the ripening of the fruit, which will affect the moisture of the biomass. The main determinant feature examined is how much extrinsic humidity it presents, because the amount of intrinsic humidity can be obtained in a laboratory. In this study extrinsic moisture has been chosen. The lower the moisture content of the material, the more that tar emissions, which tend to retain traffic exhaust and cause corrosion and clogging problems in chimneys, will be reduced [31].

\subsubsection{Physical Values: Element composition}

The UNE-EN 15104 standard has been applied to calculate the total carbon, hydrogen and nitrogen content of the sample. The elemental biomass structure is obtained burning the sample in contact with the air, in such a way that the combustion gases and ashes are acquired. Carbon contents, hydrogen, and nitrogen are expressed as mass fractions of the dry simple and are quantitatively specified using instrumental methods. A precise analysis is very relevant to precisely define the suitability of biofuel, its calorific value $(\mathrm{CV})$ and to evaluate the possible environmental impact. $\mathrm{CO}_{2}$ emissions are evaluated considering the carbon content as well as the Nitrogen content to facilitate estimation of the NOx emissions.

\subsubsection{Chemical Values: Ashes}

Another important factor in biofuel energy is ash content. The method for detecting it is based on the UNE EN 14775 standard. It is always measured with reference to the dry product and refers to the solid residue that persists after total combustion, where weight, time and temperature conditions are strictly measured. The lower the percentage of ash in the product, the greater its available energy will be. The accumulation of ash implies a greater maintenance of the boiler, due to the problems of accumulation in the deposits and corrosion in the equipment.

\subsubsection{Chemical Values: Oxygen}

The standard UNE-EN 15296 has been used to calculate the oxygen level as the remaining percentage after subtracting the percentage of the other elements (nitrogen, carbon, hydrogen sulfide and chlorine) plus the ashes. 


\subsubsection{Chemical Values: Content of Chlorine and Sulfur}

To obtain the chlorine and sulfur content, the standard UNE EN 15289 was followed, which specifies the methods for the determination of these minerals in solid biofuels. For the calculation of sulfur, the method of high temperature combustion in a tube furnace was used, together with the quantification of the gaseous products formed during combustion, a process that resembles accounting for the total content of carbon, nitrogen and hydrogen, as explained above. Chlorine, on the other hand, was obtained using digestion in a calorimetric technique. This was collected in the wash water produced by combustion and quantified by expending silver nitrate through potentiometric methods.

\subsubsection{Energy Values: Gross Heating Value and Lower Heating Value}

We can say that a biofuel is any biological material that can be burned or is not used as a source of thermal energy. This energy can be measured through a parameter known as calorific value. The total calories produced by combustion are called gross heating value (GHV) or higher heating value (HHV).

The lower heating value (LHV) which is the total amount of heat released in the complete combustion of fuel without counting the part corresponding to the latent heat of the water vapor of the combustion, since there is no phase change, but the LHV is expelled in the form of steam. The moisture content in the fuel is a determining factor, because the higher it is, the greater the contrast between HHV and LHV and the lower the total energy available.

These parameters were calculated according to UNE-EN 14918. In this study, the following equation was used to calculate the LHV without moisture from the elemental chemical composition and the constant volume of HHV [32-34].

$$
L H V\left(\frac{k J}{k g}\right)=H H V\left(\frac{k J}{k g}\right)-212.2 \times H \%-0.8 \times(O \%+N \%)
$$

where:

$H \%$ : Hydrogen content of biofuel given in \%.

$\mathrm{O} \%$ : Oxygen content of biofuel given in $\%$.

$\mathrm{N} \%$ : Nitrogen content of biofuel in $\%$.

\subsection{Boiler}

In the market there is a wide range of boilers which vary based on the type of biomass and the power required. In our case we used the date bone as fuel and the power requirements were $600 \mathrm{~kW}$, which that can be supplied by a single boiler or several boilers, installed in cascade, whose sum of powers guarantees the required value. The option of several boilers has the advantage that the eventual failure of one of them would not leave us totally without heating, which could happen with the failure of the single boiler.

With this train of thought, we could have opted for five biomass boilers of $128 \mathrm{~kW}$ nominal power, maximum marketed by the company Ökofen. Another manufacturer specializing in biomass boilers such as Hargassner offered us more possibilities to combine powers, such as five boilers of the type ECO 70-120 kW, three boilers of the type ECO 150-200 kW or two boilers of the type ECO 250-330 kW.

To ensure the proper functioning of the installation, in addition to maintenance tasks, a check of some parameters must be carried out such as:

- Water temperature and pressure at the boiler inlet and outlet.

- $\quad$ Boiler room temperature.

- $\quad$ Boiler Smoke Outlet Pressure.

- $\quad$ Flue gas temperature.

- $\quad$ Percentage of $\mathrm{CO}, \mathrm{CO}_{2}$, nitrate, sulfate in the gases. 


\section{Results and Discussion}

In order to analyze and study the energy properties of date seeds, it is very useful to compare them with other biomass residues. In this way, the assessment from the energetic point of view of the biomass heating installation is estimated.

\subsection{Date Seed Values}

With the goal of measuring and evaluating the performance values, $2000 \mathrm{~g}$ of date seeds were analyzed. Data as the mean value or the limit values are reflected in Table 1. All standards, except moisture which is referenced as wet basis, are referenced as dry basis.

Table 1. Main quality parameters for date seed derived from the test of $2000 \mathrm{~g}$ samples.

\begin{tabular}{cccccc}
\hline Magnitude & Unit & Mean Value & Standard Deviation (SD) & Maximum Value & Minimum Value \\
\hline Moisture & $\%$ & 6.5 & - & 6.5 & 6.5 \\
Ash content & $\%$ & 1.4 & 0.08 & 1.48 & 1.32 \\
HHV & $\mathrm{MJ} / \mathrm{kg}$ & 19.121 & 0.024 & 0.017 & 17.585 \\
LHV & $\mathrm{MJ} / \mathrm{kg}$ & 17.568 & 0.007 & 51.617 & 17.551 \\
Total carbon & $\%$ & 51.61 & 0.013 & 6.753 & 51.603 \\
Total hydrogen & $\%$ & 6.74 & 0.041 & 0.561 & 6.727 \\
Total nitrogen & $\%$ & 0.52 & 0.003 & 0.163 & 0.479 \\
Total sulfur & $\%$ & 0.16 & 2.427 & 43.317 & 0.157 \\
Total oxygen & $\%$ & 40.89 & 0.003 & 0.083 & 38.463 \\
Total chlorine & $\%$ & 0.08 & & 0.077 \\
\hline
\end{tabular}

The low percentage of moisture contained in the bone of the date compared to other sources is striking: this data, $6.5 \%$, greatly facilitates the drying phase and does not lengthen the whole process. This is not durable and implies that the energy efficiency in the combustion is the maximum level and there are no losses.

With regard to calorific value, only the pine pellet has a higher index than the date bone. Both the calorific value of the almond shell and that of the olive stone are lower than that of the date seed, so it would be necessary to burn more solid matter to generate the same amount of heat.

The ash content must be checked during direct combustion, as this is an unfavorable factor. The ash content in the range $1.32-1.48 \%$ may appear to be high compared to the other fossil fuels. However, in comparison with other biofuels used in biomass boilers, for example peanut shell, whose average ash content is $4.26 \%$ [23], it can be seen that the latter significantly exceeds the product under study in ashes.

Table 2 shows the quality of date seed in comparison with other common solid combustibles such as wood pellets, almond shell and olive stone. Energy parameters related to calorific value, the physical parameter moisture that influences calorific value, chemical parameters that affect the corrosion of boilers, and the ashes that are expelled during combustion, among others, have been analyzed. In view of the results it could be concluded that "date seeds" work as an optimum energy source in the form of a biomass.

Table 2. Date seed compared with other solid combustibles.

\begin{tabular}{cccccc}
\hline Variable & Unit & Date Seed & Almond Shell [35] & Olive Stone [36,37] & Wood Pellet [38] \\
\hline Moisture & $\%$ & 6.50 & 8.70 & 4.53 & 7.70 \\
HHV & $\mathrm{MJ} / \mathrm{kg}$ & 18.275 & 19.490 & 21.100 & 20.300 \\
Ash content & $\%$ & 1.40 & 2.20 & 0.6 & 0.51 \\
Total carbon & $\%$ & 46.40 & 49.30 & 49.50 & 50.3 \\
Hydrogen & $\%$ & 6.74 & 5.70 & 6.40 & 5.70 \\
Nitrogen & $\%$ & 0.52 & 0.30 & 0.20 & 0.22 \\
Oxygen & $\%$ & 40.89 & 47.50 & 40.70 & 43.57 \\
HHV biomass & $\%$ & 100.00 & 106.64 & 115.45 & 106.17 \\
\hline HHV date seed & $\%$ & &
\end{tabular}

Note: Please explain the bold numbers. 


\subsection{Energy Analysis}

The analysis has been achieved, relying on the historic need for hot water used for heating in recent years. The power required by the building is obtained from its surface area $\left(4752 \mathrm{~m}^{2}\right)$ and the average thermal load per unit area $\left(126.1 \mathrm{~W} / \mathrm{m}^{2}\right)$. With this data, a useful power of $599.23 \mathrm{~kW}$ is obtained.

Useful power $=4752 \mathrm{~m}^{2} \times 0.1261 \mathrm{~kW} / \mathrm{m}^{2}=599.23 \mathrm{~kW}$

Taking into account the operating time of heating, established in 8 hour days (in the morning from 7:30 $\mathrm{h}$ to $12: 00 \mathrm{~h}$ and in the afternoon from 16:00 $\mathrm{h}$ to 19:30 h) from Monday to Friday during the winter months, spanning approximately 16 weeks, the energy needs of the building are around $380,000 \mathrm{kWh}$ annually.

\subsection{Environment Analysis of the Biomass}

\subsection{1. $\mathrm{CO}_{2}$ Analysis}

The exploitation of biomass as a primary energy resource is carried out through a combustion process, since, if it cannot be used directly as fuel, its transformation into substances that are suitable for use in this type of process is sought [39]. It should be kept in mind that in the different processes of transformation of biomass into other combustible substances, also produce pollutants that are discharged into the environment. These include particles, carbon dioxide and monoxide, sulfur compounds, nitrogen oxides and solid and liquid waste [40]. However, unlike fossil fuels, carbon dioxide originating in the combustion process of biomass is returned to the atmosphere, from where it was taken during its generation. According to this, the use of biomass as a fuel does not increase the carbon dioxide content of the atmosphere and therefore does not contribute to the greenhouse effect. The $\mathrm{CO}_{2}$ it emits is the same as the $\mathrm{CO}_{2}$ the plant assimilated during its developing process, so this $\mathrm{CO}_{2}$ is deemed nil [41].

We can assume that plants retain more $\mathrm{CO}_{2}$ when they grow than when they release when it burns. When taking this into account, this gas has near-zero emissions. Table 3 shows how a biomass heating installation in this case could mean a total reduction of $95,760 \mathrm{~kg}$ of $\mathrm{CO}_{2}$.

Table 3. Total $\mathrm{CO}_{2}$ emission reduced.

\begin{tabular}{|c|c|}
\hline Boiler & $\mathrm{CO}_{2}(\mathrm{~kg} / \mathrm{kWh})$ \\
\hline Gas natural boiler & 0.252 \\
\hline Biomass boiler & 0 \\
\hline Total emission reduced annually (kg) & 95,760 \\
\hline
\end{tabular}

The emission of natural gas would be:

$$
\mathrm{CO}_{2 \text { natural gas }}=C_{\text {natural gas }} \times E_{\text {natural gas }}
$$

where:

$\mathrm{CO}_{2}$ natural gas: is the mass of carbon dioxide emitted ( $\mathrm{kg} /$ year).

$C_{\text {natural gas }}$ : is the consumption of natural gas in annual heating $(\mathrm{kWh} /$ year).

$E_{\text {natural gas }}$ : the carbon dioxide emission factor of natural gas $(\mathrm{kg} / \mathrm{kWh})$.

The annual consumption is $380,000 \mathrm{kWh}$ and the factor is $0.252 \mathrm{~kg} / \mathrm{kWh}$.

$$
\mathrm{CO}_{2 \text { natural gas }}=380,000 \times 0.252=95,760 \mathrm{~kg} / \text { year }
$$


Since natural gas is a source of fossil energy and knowing that the largest generation of electricity comes from a non-renewable source, it has a much higher emission factor than date bone, whereby a year's use of biomass heating would mean $\mathrm{kgs}$ of reduced $\mathrm{CO}_{2}$.

In the first 12 months, carbon dioxide emissions would be reduced by 95.76 tons. It would be highly recommended to complete a study on the energy capability of date seeds as biofuel and determine how this would impact on reducing $\mathrm{CO}_{2}$ emissions around the world. To start the study, after figuring out the calorific value of the dates seeds and after being aware of the production of the different countries per year, the power generation is calculated by applying the following formula:

$$
E_{c}=P_{c} \times f_{s} \times L H V \times U_{c}
$$

where $P_{c}$ refers to the total production, measured in $\mathrm{kg}$, of date fruits; $f_{s}$ is the seed factor in a whole date fruit $(30 \%)$; LHV is the Lower Heat Value previously determined $(17.568 \mathrm{MJ} / \mathrm{kg})$; and $U_{c}$ is the factor to convert $\mathrm{J}$ to $\mathrm{Wh}(0.000277778)$ and $E_{\mathcal{C}}(\mathrm{MWh})$ is the power that would be obtained with all the date fruits generated.

If we choose Spain as an example, date fruits production was $2996 \mathrm{t}$ in 2016 . With this amount of production, we could generate a total of $4386.15 \mathrm{MWh}$. So, considering that the total production around the world of date fruits seed was 8460.443 tons, the energy generated that would be obtained with this date seeds is appraised at 12,386.25 GWh.

Therefore, we could say that the total energy generation potential of the countries is reached using this equation. Figure 3 shows the energy generation through the different countries producing date fruits. We can see that countries such as Egypt, Iran and Algeria have a greater energy potential in comparison with other countries around Europe. As we can see, the zone between Africa and Asia has several countries with great potential. In Asia, Pakistan is the country with the largest energy production capacity, while in the Americas just Mexico, Peru and Colombia have some potential in this area.

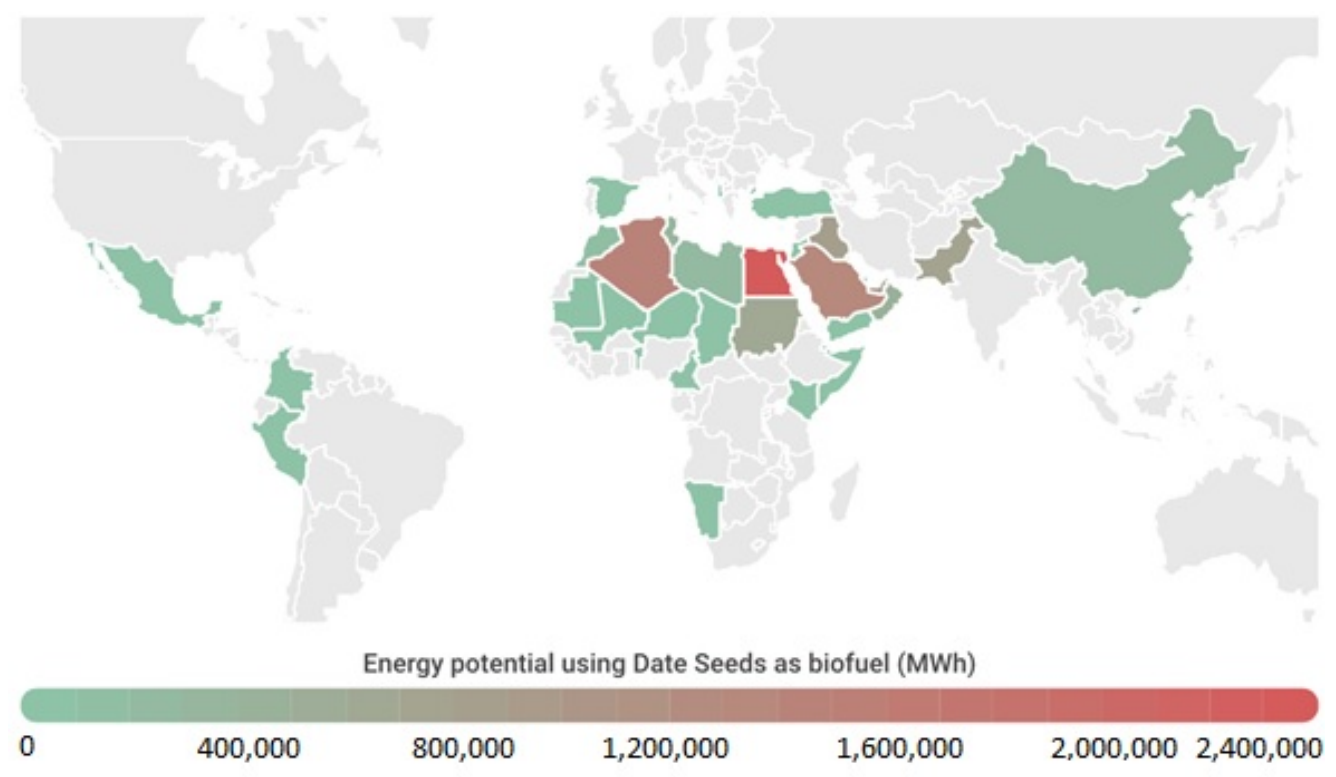

Figure 3. Energy produced using date seeds as biofuel (MWh).

In order to analyze the potential of date seeds to reduce $\mathrm{CO}_{2}$ emissions, emissions data from fossil fuels must be considered. These data are obtained in the World Data Bank, and with this information we can affirm that for each MWh generated, $357 \mathrm{~kg}$ of $\mathrm{CO}_{2}$ are expelled into the atmosphere.

Not surprisingly, countries with higher date production have a higher energy production potential. This also means greater potential for reducing $\mathrm{CO}_{2}$ emissions. The countries with a greater production 
in dates are: Egypt with almost 1.7 million tons, followed by Iran (1.1 million tons), Algeria (1 million tons), Saudi Arabia (0.9 million tons), the United Arab Emirates (0.7 million tons), Iraq (0.6 million tons) and Pakistan (0.5 million tons) [42].

On the other hand, when comparing the total $\mathrm{CO}_{2}$ emissions of each country according to the world data bank with the total $\mathrm{CO}_{2}$ emissions reduction associated with the use of date seeds, we see that the data vary. The countries with the highest percentage are in the north of Africa. These countries are Sudan, with almost $15 \%$ of the total, Chad (14.3\%), Somalia (11.5\%), Niger (4.6\%), Egypt (4.4\%) or Mauritania (4.3\%).

\subsubsection{Particle size emissions}

Until recently combustion plants such as thermal power plants had a control of total particulate emissions, i.e. $\mathrm{PM}_{10}$ [43]. However, it has been demonstrated that for human health the emissions of particles of a smaller size are even more harmful. $\mathrm{PM}_{2.5}$ and $\mathrm{PM}_{5}$ [44], already present a greater health risk due to their high penetration capacity in the respiratory tract, particularly in the case of the former [45]. The latter have an anthropogenic origin in a high proportion since they come largely from emissions from diesel vehicles in cities [46].

Regarding the levels of air quality in the study area, i.e. compliance with European regulations and their transposition into Spanish legislation, compliance with the annual limit value of $\mathrm{PM}_{10}$, there should be no more than 35 days per year exceeding the limit value of $50 \mu \mathrm{g} / \mathrm{m}^{3}$ in $24 \mathrm{~h}$, established on the compliance date in January 2005 [47].

There is a European directive, Directive (EU) 2015/2193 of the European Parliament and of the Council of 25 November 2015 [48], concerning the limitation of emissions of specific pollutants into the air from medium-sized combustion plants. This regulation can be applied to facilities with a nominal thermal input equal to or greater than $1 \mathrm{MW}$ and less than or equal to $5 \mathrm{MW}$, i.e. those considered as average combustion plants. It states that until 1 January 2030, Member States may exempt medium-sized combustion plants that are using solid biomass as their main fuel, the idea of the legal regulation being to increase the use of biomass as a fuel. For plants burning exclusively solid woody biomass, the limits for various gases such as $\mathrm{SO}_{2}$ are not applicable. There are studies showing that certain reprocessing methods such as torrefaction can significantly improve the HHV and reduce emissions. As an example, HHV increased for pine shells by $25 \%$ and for olive pits by $18 \%$ [49]. This is because when there are higher temperatures there are higher emissions and above all $\mathrm{PM}_{2.5}$, therefore the boiler operating temperature has a great influence on the total particles $\left(\mathrm{PM}_{10}\right)$.

\subsection{Economical Balance}

In order to compare from an economical perspective, the old natural gas installation and the new one, a comparative analysis has been carried out that analyzes the cost per year required to cover the total energy demanded by the university building with each of the combustibles: natural gas or biomass. Table 4 shows both the total liters of the gas that is consumed in the previous installation per year and the annual expense.

Table 4. Cost of thermal energy demand with each of the fuels, natural gas and biomass.

\begin{tabular}{ccc}
\hline Magnitude & Natural gas & Date seeds \\
\hline LHV & $13.1 \mathrm{kWh} / \mathrm{kg}$ & $4.88 \mathrm{kWh} / \mathrm{kg}$ \\
Combustible price & $5.85 \cdot 10^{-4} € / \mathrm{L}$ & $0.09 € / \mathrm{kg}$ \\
Efficiency of the boiler & $90 \%$ & $80 \%$ \\
Useful power & $600 \mathrm{~kW}$ & $600 \mathrm{~kW}$ \\
Running hours & $634 \mathrm{~h}$ & $634 \mathrm{~h}$ \\
Heating demand & $380,000 \mathrm{kWh} /$ year & $380,000 \mathrm{kWh} /$ year \\
Consumption & $42,945,350.43 \mathrm{~L}$ & $93,442.62 \mathrm{~kg}$ \\
Cost per year & $25,123.03 €$ & $8409.84 €$ \\
\hline
\end{tabular}


Knowing the value of the annual heating demand, the consumption of biomass is calculated with the following formula:

$$
B_{\text {year }}=C_{\text {year }} / \mathrm{LHV}
$$

where:

$B_{\text {year }}$ : Biomass consumed in one year $(\mathrm{kg} /$ year $)$.

$C_{\text {year }}$ : Annual heating consumption ( $\mathrm{kWh} /$ year).

LHV: Lower heating value of biomass $(\mathrm{kWh} / \mathrm{kg})$.

The annual heating consumption is $380,000 \mathrm{kWh}$ and the LHV is $4.88 \mathrm{kWh} / \mathrm{kg}$.

Thus, $93,442.62 \mathrm{~kg}$ of solid biomass are consumed per year, considering the efficiency of the boiler.

While it is true that the gas is clean fuel in daily operation and does not require much maintenance, two decisive factors such as automation and technological advances, on the one hand, and the competitive price, on the other, make it profitable and beneficial to switch from gas to biomass boilers currently. The price of gas is raising, particularly in some countries with an increased level of taxes and this is levied on fossil combustibles. This causes solid biofuels to be considered as a useful alternative not only for the economy, but also for ecology, safety and comfort reasons. Bearing in mind that the cost of biomass is $0.09 € / \mathrm{kg}$, the analysis reveals an annual cost of $8409.84 €$ with the use of date seed as biofuel versus $25,123.03 €$ as the cost of maintaining the facility with natural gas. Therefore, using date seed as a biofuel entails an annual saving of $16,713.19 €$, representing a savings percentage of $66.53 \%$.

\section{Conclusions}

The study concludes that the viability of date seed as an alternative source of energy is feasible. The study asses the physical aspects of date seeds and highlights the high level of volatile matter if it is used as fuel. Numerous combustion experiments have been carried out, in which the high rate of gasification has been verified, and in the case of occurring in high combustion air conditions, combustion rates and heat transfer are multiplied. In this study the characteristics of date seeds have been compared with other fuels such as coal, obtaining a higher combustion rate per unit of mass for date seeds. The same applies to heat transfer. This is due to the high levels of volatile matter in date bone. In addition to this, date seeds have a low ash content, allowing more direct combustion in the furnaces.

It is a global goal for all countries to reduce of energy consumption. This is a challenge to be achieved in the coming years and therefore measures must be taken to improve this problem immediately. With this research a waste product such as date bone has been evaluated and in doing so adds a new clean energy form that can be used as fuel. The study shows that replacing a natural gas boiler with a biomass one and using the date bone as biofuel, we would obtain an annual saving of $95,760 \mathrm{~kg}$ of $\mathrm{CO}_{2}$. In addition, the calorific power of the date bone gives it optimal properties as a source of thermal energy comparable to other biofuels currently being marketed.

It is a reality that most buildings have small independent boilers to cover the heating needs of each building and for that reason the total installed power is much higher than what is needed. A good way to save energy is to centralize the heating system of the entire campus. This would increase the coefficient of simultaneity to reduce the installed power and at the same time reduce the loss in combustion of the raw material. This study could contemplate a next phase in a future focused on analyzing the centralization of the system in the campus. Other additional phases could be the study of other waste products as biofuel in biomass boilers and expand the production of this type of renewable energy to other types of buildings.

Author Contributions: C.d.l.C.-L. dealt with the literature review and article writing. J.-L.d.l.C.-F. and E.S.-M. analyzed the data. F.M.-A. and A.-J.P.-M.: Research idea, article writing and formatting. They share the structure and aims of the manuscript, paper drafting, editing and review. All authors have read and approved the final manuscript. 
Funding: This research received no external funding.

Conflicts of Interest: The authors declare no conflict of interest.

\section{References}

1. Roy, S.; Ragunath, S. Emerging Membrane Technologies for Water and Energy Sustainability: Future Prospects, Constraints and Challenges. Energies 2018, 11, 2997. [CrossRef]

2. Tronchin, L.; Manfren, M.; Nastasi, B. Energy efficiency, demand side management and energy storage technologies-A critical analysis of possible paths of integration in the built environment. Renew. Sustain. Energy Rev. 2018, 95, 341-353. [CrossRef]

3. Demirbas, A. Energy issues and energy priorities. Energy Sources B Econ. Plan. Policy 2007, 3, 41-49. [CrossRef]

4. Banos, R.; Manzano-Agugliaro, F.; Montoya, F.; Gil, C.; Alcayde, A.; Gómez, J. Optimization methods applied to renewable and sustainable energy: A review. Renew. Sustain. Energy Rev. 2011, 15, 1753-1766. [CrossRef]

5. Tumlison, C.; Button, E.D.; Song, G.; Kester, J. What explains local policy elites' preferences toward renewable energy/energy efficiency policy? Energy Policy 2018, 117, 377-386. [CrossRef]

6. Bronselaer, B.; Winton, M.; Griffies, S.M.; Hurlin, W.J.; Rodgers, K.B.; Sergienko, O.V.; Russell, J.L. Change in future climate due to Antarctic meltwater. Nature 2018, 564, 53. [CrossRef] [PubMed]

7. Montoya, F.G.; Peña-García, A.; Juaidi, A.; Manzano-Agugliaro, F. Indoor lighting techniques: An overview of evolution and new trends for energy saving. Energy Build. 2017, 140, 50-60. [CrossRef]

8. Allouhi, A.; El Fouih, Y.; Kousksou, T.; Jamil, A.; Zeraouli, Y.; Mourad, Y. Energy consumption and efficiency in buildings: Current status and future trends. J. Clean. Prod. 2015, 109, 118-130. [CrossRef]

9. Manzano-Agugliaro, F.; Montoya, F.G.; Sabio-Ortega, A.; García-Cruz, A. Review of bioclimatic architecture strategies for achieving thermal comfort. Renew. Sustain. Energ. Rev. 2015, 49, 736-755. [CrossRef]

10. AlFaris, F.; Juaidi, A.; Manzano-Agugliaro, F. Improvement of efficiency through an energy management program as a sustainable practice in schools. J. Clean. Prod. 2016, 135, 794-805. [CrossRef]

11. AlFaris, F.; Juaidi, A.; Manzano-Agugliaro, F. Energy retrofit strategies for housing sector in the arid climate. Energy Build. 2016, 131, 158-171. [CrossRef]

12. De la Cruz-Lovera, C.; Perea-Moreno, A.-J.; de la Cruz-Fernández, J.-L.; Alvarez-Bermejo, J.A.; Manzano-Agugliaro, F. Worldwide research on energy efficiency and sustainability in public buildings. Sustainability 2017, 9, 1294. [CrossRef]

13. AlFaris, F.; Juaidi, A.; Manzano-Agugliaro, F. Intelligent homes' technologies to optimize the energy performance for the net zero energy home. Energy Build. 2017, 153, 262-274. [CrossRef]

14. Zhao, L.; Zhou, Z. Developing a rating system for building energy efficiency based on in situ measurement in China. Sustainability 2017, 9, 208. [CrossRef]

15. Olesen, B.W. Revision of EN 15251: Indoor environmental criteria. REHVA J. 2012, 49, 6-12.

16. Ekren, O.; Karadeniz, Z.H.; Atmaca, İ.; Ugranli-Cicek, T.; Sofuoglu, S.C.; Toksoy, M. Assessment and improvement of indoor environmental quality in a primary school. Sci. Technol. Built Environ. 2017, 23, 391-402. [CrossRef]

17. Pepler, R.D. Temperature and learning: An experimental study. ASHRAE Trans. 1968, 74, 211-224.

18. Klass, D.L. Biomass for Renewable Energy, Fuels, and Chemicals; Elsevier: Amsterdam, The Netherlands, 1998.

19. Li, G.; Liu, C.; Yu, Z.; Rao, M.; Zhong, Q.; Zhang, Y.; Jiang, T. Energy Saving of Composite Agglomeration Process (CAP) by Optimized Distribution of Pelletized Feed. Energies 2018, 11, 2382. [CrossRef]

20. Williams, O.; Taylor, S.; Lester, E.; Kingman, S.; Giddings, D.; Eastwick, C. Applicability of Mechanical Tests for Biomass Pellet Characterisation for Bioenergy Applications. Materials 2018, 11, 1329. [CrossRef]

21. Perea-Moreno, A.-J.; Perea-Moreno, M.-Á.; Dorado, M.P.; Manzano-Agugliaro, F. Mango stone properties as biofuel and its potential for reducing CO2 emissions. J. Clean. Prod. 2018, 190, 53-62. [CrossRef]

22. Perea-Moreno, A.-J.; Aguilera-Ureña, M.-J.; Manzano-Agugliaro, F. Fuel properties of avocado stone. Fuel 2016, 186, 358-364. [CrossRef]

23. Perea-Moreno, M.A.; Manzano-Agugliaro, F.; Perea-Moreno, A.J. Sustainable energy based on sunflower seed husk boiler for residential buildings. Sustainability 2018, 10, 3407. [CrossRef]

24. Saidur, R.; Abdelaziz, E.; Demirbas, A.; Hossain, M.; Mekhilef, S. A review on biomass as a fuel for boilers. Renew. Sustain. Energy Rev. 2011, 15, 2262-2289. [CrossRef] 
25. Lala, S.; Amri, A.; Maxted, N. Towards the conservation of crop wild relative diversity in North Africa: Checklist, prioritisation and inventory. Genet. Resour. Crop Evol. 2018, 65, 113-124. [CrossRef]

26. Al-Alawi, R.A.; Al-Mashiqri, J.H.; Al-Nadabi, J.S.M.; Al-Shihi, B.I.; Baqi, Y. Date Palm Tree (Phoenix dactylifera L.): Natural Products and Therapeutic Options. Front. Plant Sci. 2017, 8, 845. [CrossRef] [PubMed]

27. Agoudjil, B.; Benchabane, A.; Boudenne, A.; Ibos, L.; Fois, M.J.E. buildings, Renewable materials to reduce building heat loss: Characterization of date palm wood. Energy Build. 2011, 43, 491-497. [CrossRef]

28. FAO. FAO Statistical Yearbook: World Food and Agriculture; FAO: Rome, Italy, 2013; Available online: http:/ / www.fao.org/docrep/018/i3107e/i3107e.PDF (accessed on 20 September 2018).

29. Elmay, Y.; Trouvé, G.; Jeguirim, M.; Said, R. Energy recovery of date palm residues in a domestic pellet boiler. Fuel Process. Technol. 2013, 112, 12-18. [CrossRef]

30. Álvarez-Álvarez, P.; Pizarro, C.; Barrio-Anta, M.; Cámara-Obregón, A.; Bueno, J.L.M.; Álvarez, A.; Gutiérrez, I.; Burslem, D.F.R.P. Evaluation of Tree Species for Biomass Energy Production in Northwest Spain. Forests 2018, 9, 160. [CrossRef]

31. Nogués, F.S. Energía de la Biomasa (Volumen I); Universidad de Zaragoza: Zaragoza, Spain, 2010; Volume 173.

32. Khan, A.; De Jong, W.; Jansens, P.; Spliethoff, H. Biomass combustion in fluidized bed boilers: Potential problems and remedies. Fuel Process. Technol. 2009, 90, 21-50. [CrossRef]

33. Senelwa, K.; Sims, R.E. Bioenergy, Fuel characteristics of short rotation forest biomass. Biomass Bioenerg. 1999, 17, 127-140. [CrossRef]

34. Nasser, R.A.-S.; Aref, I.M. Fuelwood characteristics of six acacia species growing wild in the southwest of Saudi Arabia as affected by geographical location. BioResources 2014, 9, 1212-1224. [CrossRef]

35. García, R.; Pizarro, C.; Lavín, A.G.; Bueno, J.L. Biomass sources for thermal conversion. Techno-economical overview. Fuel 2017, 195, 182-189. [CrossRef]

36. Sánchez, F.; San Miguel, G. Improved fuel properties of whole table olive stones via pyrolytic processing. Biomass Bioenerg. 2016, 92, 1-11. [CrossRef]

37. Bartocci, P.; D'Amico, M.; Moriconi, N.; Bidini, G.; Fantozzi, F. Pyrolysis of olive stone for energy purposes. Energy Procedia 2015, 82, 374-380. [CrossRef]

38. Obernberger, I.; Thek, G. Physical characterisation and chemical composition of densified biomass fuels with regard to their combustion behaviour. Biomass Bioenerg. 2004, 27, 653-669. [CrossRef]

39. Mugica-Álvarez, V.; Hernández-Rosas, F.; Magaña-Reyes, M.; Herrera-Murillo, J.; Santiago-De La Rosa, N.; Gutiérrez-Arzaluz, M.; Figueroa-Lara, J.J.; González-Cardoso, G. Sugarcane burning emissions: Characterization and emission factors. Atmos. Environ. 2018, 193, 262-272. [CrossRef]

40. Younis, M.; Alnouri, S.Y.; Abu Tarboush, B.J.; Ahmad, M.N. Renewable biofuel production from biomass: A review for biomass pelletization, characterization, and thermal conversion techniques. Int. J. Green Energy 2018, 15, 837-863. [CrossRef]

41. Rabczak, S.; Proszak-Miasik, D. Effect of the type of heat sources on carbon dioxide emissions. J. Ecol. Eng. 2016, 17, 186-191. [CrossRef]

42. FAOSTAT. Agriculture Data. 2016. Available online: http://www.fao.org/faostat/en/\#home (accessed on 15 September 2018).

43. Manzano-Agugliaro, F.; Carrillo-Valle, J. Conversion of an existing electrostatic precipitator casing to Pulse Jet Fabric filter in fossil power plants. Dyna 2016, 83, 189-197. [CrossRef]

44. Lu, F.; Xu, D.; Cheng, Y.; Dong, S.; Guo, C.; Jiang, X.; Zheng, X. Systematic review and meta-analysis of the adverse health effects of ambient PM2.5 and PM10 pollution in the Chinese population. Environ. Res. 2015, 136, 196-204. [CrossRef]

45. Xing, Y.F.; Xu, Y.H.; Shi, M.H.; Lian, Y.X. The impact of PM2.5 on the human respiratory system. J. Thorac. Dis. 2016, 8, e69. [PubMed]

46. He, K.; Yang, F.; Ma, Y.; Zhang, Q.; Yao, X.; Chan, C.K.; Cadle, S.; Chan, T.; Mulawa, P. The characteristics of PM2.5 in Beijing, China. Atmos. Environ. 2001, 35, 4959-4970. [CrossRef]

47. Spanish Law. Real Decreto 1073/2002, de 18 de Octubre, Sobre Evaluación y Gestión de la Calidad del Aire Ambiente en Relación con el Dióxido de Azufre, Dióxido de Nitrógeno, Óxidos de Nitrógeno, Partículas, Plomo, Benceno y Monóxido de Carbono. Available online: https:/ / www.boe.es/buscar/doc.php?id=BOEA-2002-20933 (accessed on 7 October 2018). 
48. Directive (EU) 2015/2193 of the European Parliament and of the Council of 25 November 2015 on the Limitation of Emissions of Certain Pollutants into the Air from Medium Combustion Plants. Available online: https: / / eur-lex.europa.eu/legal-content/ES/TXT/?uri=CELEX\%3A32015L2193 (accessed on 15 December 2018).

49. García, R.; Pizarro, C.; Álvarez, A.; Lavín, A.G.; Bueno, J.L. Study of biomass combustion wastes. Fuel 2015, 148, 152-159. [CrossRef] 